\title{
Molten Fluoride Salt and Liquid Metal Multistage Extraction Model
}

\author{
William Cohen, Wentao Zhou, Evan Wu, Jinsuo Zhang* \\ Nuclear Engineering Program, Department of Mechanical and Aerospace Engineering \\ The Ohio state University
}

\begin{abstract}
A multistage extraction model based on the distribution of actinides and rare earths between two phases of lithium activated bismuth and molten $\mathrm{LiF}_{-} \mathrm{BeF}_{2}(66$ mole \% $\mathrm{LiF}$ ) has been developed. The model shows that the distribution across the cascade is affected by the concentration of $\mathrm{Li}$ in the metal phase, system temperature, flow rates of each phase, and the presence and concentration of other elements in the molten salt phase. Based on the model, it is predicted that an online molten salt coolant purification system could be used to separate both rare earths and actinides from the primary salt coolant in fluoride salt-cooled hightemperature reactors (FHRs). Additionally, the results provide sufficient evidence that this extraction method can separate primarily actinides prior to extraction of other rare earth elements, which would allow for fission products and other reactor poisons to be discarded, while fuel materials ( $\mathrm{U}$ and $\mathrm{Pu}$ ) can be recycled back into a reactor system.
\end{abstract}

Keywords: Liquid-Liquid Extraction, Salt-cooled Nuclear Reactor, Cleanup System

*Corresponding Author: Dr. Jinsuo Zhang, Email: zhang.3558@ osu.edu 


\section{Introduction}

The fluoride salt-cooled high-temperature reactor, FHR, has acquired interest as a GEN IV reactor candidate with potential to be manufactured as a commercial power reactor. The conceptual design and research objectives of FHR technology have been previously reported [1]. A major concern for FHR development is the likelihood of contamination in the primary coolant. Uranium, alkali metals, alkaline earths, and rare earth elements all form stable fluoride compounds, as such, salt-seeking elements from leaking fuel would contaminate the primary coolant $[2,3]$. Therefore, a continuous online cleanup system is necessary to ensure the continued operation of the reactor, while also minimizing the volume of salt coolant waste. Leaked fission products and transuranic materials from the fuel are a major source of this contamination [2,3]. The use of a liquid metal reducing agent, such as bismuth with dissolved lithium, has been identified as a good removal technology in Molten Salt Breeder Reactors, and has been proposed as a clean-up method for FHR primary coolant [4,5].

A previously developed distribution model for the removal of actinides and rare earths from chloride salt using lithium activated bismuth has been modified and adapted as part of this study [6]. A new model has been developed to simulate a multistage extraction system for the removal of actinides and rare earths from a eutectic mixture of $\mathrm{LiF}^{-\mathrm{BeF}_{2}}(66 \% \mathrm{LiF})$ salt using the same reductive extractant. The model predicts the distribution of actinides and rare earths between the fluoride salt and liquid metal at each stage using experimentally determined data for the apparent potential and activity coefficients of each contaminant in both phases. All stages are assumed to have a residence time large enough for equilibrium to be reached and electrochemical kinetics are therefore not considered. However, previous experiments and studies show that the time scale for reaching equilibration in a batch system is on the order of a few hours to a couple days [7, 8]. This is a significant challenge that will need to be addressed in order for the continuous extraction process described in this paper to be advantageous. The development of equipment to decrease the equilibration time will be necessary. Possible solutions could be to use a series of centrifugal contactors or pulse columns [9] to mix the liquids during the separation. The centrifugal contactor and the pulse column have been successfully applied in liquid-liquid separation in PUREX for used fuel reprocessing.

The salt-seeking elements include actinides and rare earths, such as $\mathrm{U}, \mathrm{Pu}, \mathrm{Y}, \mathrm{La}, \mathrm{Ce}, \mathrm{Pr}, \mathrm{Nd}$, $\mathrm{Pm}, \mathrm{Gd}, \mathrm{Tb}, \mathrm{Dy}, \mathrm{Ho}, \mathrm{Er}, \mathrm{Zr}, \mathrm{Sm}, \mathrm{Eu}, \mathrm{Sr}, \mathrm{Ba}, \mathrm{Rb}$, and Cs [2]. However, based on limitations of available electrochemical data in fluoride salt, the model can currently predict the distribution across any number of stages for a combination of up to two actinides ( $\mathrm{U}$ and $\mathrm{Pu}$ ) and three rare earths ( $\mathrm{La}, \mathrm{Ce}$, and $\mathrm{Sm}$ ). The model has the capability to be expanded to include additional elements, if necessary data becomes available in the future. The remainder 
of this paper will discuss the methods and equations used in the development of the model and the efficacy and plausibility of this multistage extraction system based on the results.

\section{Molten Salt/Liquid Metal Distribution 2.1 Equilibrium Model for One Stage}

In a molten salt/ liquid metal system, reductive extraction can be applied to remove metal elements from the salt phase. For the case of an FHR using $\mathrm{LiF}_{-} \mathrm{BeF}_{2}$ as the primary coolant, lithium activated bismuth can be used to reduce metallic fluorides through the reaction shown below.

$$
M F_{n}+n L i \leftrightarrow M+n L i F \quad \text { Eq. } 1
$$

where $M$ denotes the metal species being reduced and $n$ is the oxidation state of the oxidized metal. The Nernst equation can be used to describe the equilibrium potential of the reaction

$$
E_{e q}=E_{M^{n+}}^{a p}+\frac{R T}{n F} \ln \left(\frac{X_{M^{n+}}}{\gamma_{M} Y_{M}}\right)
$$

where $E_{e q}$ and $E_{M^{n+}}^{a p}$ are the equilibrium potential and the apparent standard potential, respectively, $R$ is the gas constant, $F$ is Faraday's constant, $X_{M^{n+}}$ is the molar fraction of the metallic fluoride in the molten salt, $\gamma_{M}$ is the activity coefficient of metal $\mathrm{M}$ in bismuth and $Y_{M}$ is the molar fraction of the metal in the liquid metal.

The distribution coefficient can be defined as the ratio of the concentration of metal $\mathrm{M}$ in the salt phase $\left(X_{M^{n+}}\right)$ to the concentration of metal $\mathrm{M}$ in the metal phase $\left(Y_{M}\right)$. Rearranging the above equation gives

$$
D_{M}=\frac{X_{M^{n+}}}{Y_{M}}=\gamma_{M} \exp \left(\frac{n F}{R T}\left(E_{e q}-E_{M^{n+}}^{a p}\right)\right)
$$

For a multi-contaminant system with multiple metallic fluorides dissolved in the molten salt, the equilibrium potential, $E_{e q}$, must be equal for all species. Therefore, the distribution coefficient for each rare earth and actinide is driven by the concentrations of all other elements within the molten salt/liquid metal system. Molar balances across a single stage are shown below, assuming that there are initially no rare earths or actinides in the liquid metal phase and that the change in volume of the molten salt and liquid metal phases as ions are transferred is negligible. 


$$
\begin{array}{cc}
B i_{\text {feed }} Y_{M_{i}}+\text { Salt }_{\text {feed }} X_{M_{i}^{n_{i}+}}=\text { Salt }_{\text {feed }} X_{M_{i}^{n_{i}}}^{I} & \text { Eq. } 4 \\
B i_{\text {feed }} Y_{L i}+\text { Salt }_{\text {feed }} X_{L^{+} i^{+}}=\text {Salt }_{\text {feed }} X_{L i^{+}}^{I} B i_{\text {feed }} Y_{L i}^{I} & \text { Eq. } 5 \\
\sum_{i=1}^{m} B i_{f e e d} n_{i} Y_{M_{i}}=B i_{f e e d} Y_{L i}^{I}-B i_{\text {feed }} Y_{L i} & \text { Eq. } 6
\end{array}
$$

where $B i_{f e e d}$ and $S a l t_{f e e d}$ are the volumetric flow rates of the liquid bismuth phase and molten fluoride salt phase, respectively, the superscript "I" denotes the initial concentration, and $m$ is the total number of metal elements in the system. Combining the molar balance equations with the first half of the equation for distribution coefficient gives:

$$
\sum_{i=1}^{m} \frac{n_{i} X_{M_{i}^{n_{i}}}^{I}}{B i_{\text {feed }}+\text { Salt }_{\text {feed }} D_{M_{i}}}=\frac{Y_{L i}^{I} D_{L i}-X_{L i^{+}}^{I}}{B i_{\text {feed }}+\text { Salt }_{\text {feed }} D_{L i}}
$$

With specified initial concentrations for each element (including lithium), the only unknown variables are the corresponding distribution coefficients at equilibrium. The previously shown equation for distribution coefficient shows that for a specified temperature, the equilibrium potential, $E_{e q}$, is the only unknown. Since the equilibrium potential is constant within the system for all present elements at every stage, the above equation has only one unknown variable.

\subsection{Apparent Potential in LiF-BeF 2 Molten Salt}

In order to accurately predict the distribution of rare earths and actinide elements, the apparent potential of each element in the salt phase must be known. The apparent potential has been shown to be dependent on temperature in previous studies and can be expressed in the form shown below.

$$
E_{M^{n+}}^{a p}=A+B T
$$

Eq. 8

where $\mathrm{A}$ and $\mathrm{B}$ are experimental constants and $\mathrm{T}$ is temperature in Kelvin. Data has been collected from previous experiments and are reported in Table 1. All literature data is valid for $\mathrm{LiF}-\mathrm{BeF}_{2}(66 \% \mathrm{LiF})$ within the temperature range of 600 to $800^{\circ} \mathrm{C}$. 
Table 1. Experimentally Determined Apparent Potentials of Rare Earths and Actinides in LiF-BeF2 Molten Salt

\begin{tabular}{|l|l|l|l|l|}
\cline { 2 - 5 } \multicolumn{1}{c|}{} & \multirow{2}{*}{ Oxidation State } & \multicolumn{2}{|c|}{ Apparent Potential in Salt } & \multirow{2}{*}{ Reference } \\
\cline { 2 - 5 } \multicolumn{1}{c|}{} & & Const. A (V) & Const. B (V/K) & \\
\hline $\mathbf{U}$ & 3 & $-2.06 \mathrm{E}+00$ & $6.26 \mathrm{E}-04$ & {$[10]$} \\
\hline $\mathbf{P u}$ & 3 & $-2.31 \mathrm{E}+00$ & $7.88 \mathrm{E}-04$ & {$[11]$} \\
\hline La & 3 & $-3.03 \mathrm{E}+00$ & $8.21 \mathrm{E}-04$ & {$[10]$} \\
\hline Ce & 3 & $-2.96 \mathrm{E}+00$ & $8.17 \mathrm{E}-04$ & {$[12,13]$} \\
\hline Sm & 3 & $-2.81 \mathrm{E}+00$ & $7.95 \mathrm{E}-04$ & {$[12,13]$} \\
\hline $\mathbf{L i}$ & 1 & $-3.362 \mathrm{E}+00$ & $8.21 \mathrm{E}-04$ & {$[10]$} \\
\hline
\end{tabular}

\subsection{Activity Coefficient in Bi Liquid Metal}

In addition to the apparent potential in the salt phase, the activity coefficient in the liquid metal phase must also be known. The activity coefficient, which is also temperature dependent, can be expressed using the equation below.

$$
\ln \gamma=A-\frac{B}{T}
$$

Eq. 9

where $\mathrm{A}$ and $\mathrm{B}$ are experimental constants and $\mathrm{T}$ is temperature in Kelvin. Data has been collected from previous experiments and are reported in Table 2. As with apparent potential literature data, all activity coefficient data is valid for liquid bismuth metal within the temperature range of 600 to $800^{\circ} \mathrm{C}$.

Table 2. Experimentally Determined Activity Coefficients of Rare Earths and Actinides in Liquid Bismuth Metal

\begin{tabular}{|l|l|l|l|l|}
\cline { 2 - 5 } \multicolumn{1}{c|}{} & \multirow{2}{*}{ Oxidation State } & \multicolumn{2}{|l|}{ Activity Coefficient in Bi } & \multirow{2}{*}{ Reference } \\
\cline { 3 - 5 } \multicolumn{1}{l|}{} & & Const. A & Const. B (K) & \\
\hline $\mathbf{U}$ & 3 & $2.39 \mathrm{E}+00$ & $1.00 \mathrm{E}+04$ & {$[14]$} \\
\hline $\mathrm{Pu}$ & 3 & $3.43 \mathrm{E}+00$ & $1.93 \mathrm{E}+04$ & {$[15]$} \\
\hline $\mathrm{La}$ & 3 & $3.11 \mathrm{E}+00$ & $2.63 \mathrm{E}+04$ & {$[16]$} \\
\hline $\mathrm{Ce}$ & 3 & $3.82 \mathrm{E}+00$ & $2.61 \mathrm{E}+04$ & {$[16]$} \\
\hline $\mathrm{Sm}$ & 3 & $4.03 \mathrm{E}+00$ & $2.71 \mathrm{E}+04$ & {$[16]$} \\
\hline
\end{tabular}


The activity coefficient of lithium in bismuth has also been reported in literature [17]. However, the activity coefficient does not follow the form used above for $\mathrm{LiF}_{-} \mathrm{BeF}_{2}$ salt. The expression for activity coefficient can be seen below and is reported to be valid within the temperature range of 775 to $1100 \mathrm{~K}$ (approximately 500 to $825^{\circ} \mathrm{C}$ ).

$$
\begin{aligned}
\ln \left(\gamma_{L i}\right)=-4.262+.787 T-4.72 * 10^{-4} T^{2} & \\
+ & \left(307.72-.842 T+2.94 * 10^{-4} T^{2}\right) * Y_{L i}
\end{aligned}
$$

Based on the expression, along with temperature, concentration of $\mathrm{Li}$ is also significant contributing factor in the activity coefficient in liquid bismuth.

\section{Multistage Extraction Model}

A continuous multistage extraction model is the proposed method for online primary coolant reprocessing. The described process will include multiple equilibrium stages with a fresh liquid metal stream at each stage. The product molten salt stream from each stage will be fed to the inlet of the next stage. A schematic diagram for the extraction cascade can be seen below in Figure 1, where $\mathrm{N}$ is the total number of stages, $X_{M_{i}, n}$ is the concentration of element $M_{i}$ in the molten salt outlet of the $n^{\text {th }}$ stage, and $Y_{M_{i}, n}$ is the concentration of element $M_{i}$ in the liquid metal outlet of the $n^{\text {th }}$ stage.

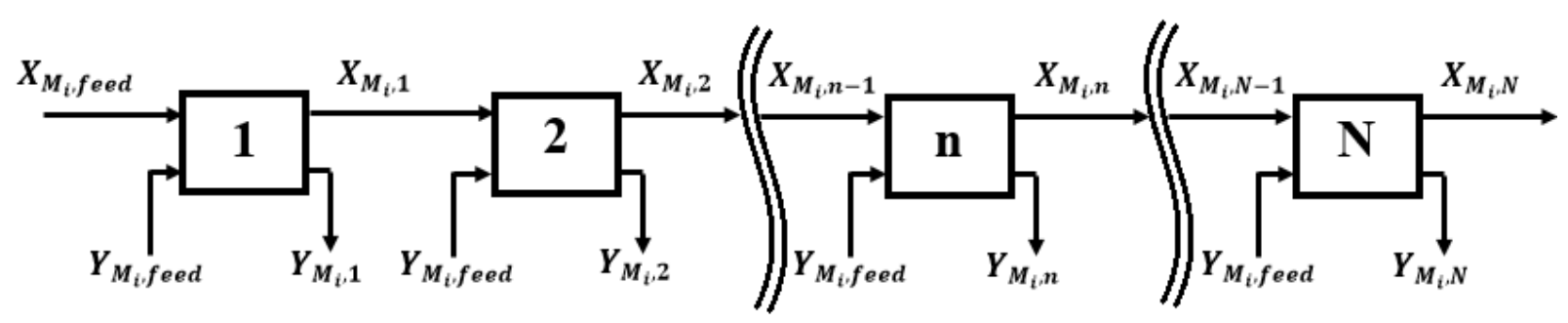

Figure 1. Flowchart Diagram of Multistage Extraction System

The distribution coefficient for each element $M_{i}$ describes the final equilibrium state and can therefore be represented based on the final concentrations in the two phases at the outlet of each stage $n$.

$$
D_{n}=\frac{X_{M_{i}, n}}{Y_{M_{i}, n}}
$$

The single stage equations shown in Section 2.1 hold valid and can be applied to each stage. The equilibrium potential and distribution coefficients of all solutes at each stage can then be determined. Using the molar balances, the distribution coefficients can be used to determine 
the concentrations of solutes in each phase. Then, the recovery yield for each solute at each stage can be expressed by

$$
\zeta_{M_{i}, n}=\frac{X_{M_{i}, \text { feed }}-X_{M_{i}, n}}{X_{M_{i}, \text { feed }}} * 100
$$

\section{Results and Discussion}

During FHR operation, radionuclides from the fuel will inevitably leak into the primary fluoride salt coolant. These contaminants will be present in very low concentrations. Based on previous experiments all contaminants were either less than .002 mole fraction or a major component of the salt ( $\mathrm{LiF}$ and $\left.\mathrm{BeF}_{2}\right)$ [18]. Therefore, .001 was used as the mole fraction for each actinide and rare earth for this model. The metal phase for each stage was specified to have an initial lithium concentration of .001 mole fraction. The flow rates of each phase are not empirically set in the model; however the ratio of the molten salt feed stream to liquid bismuth metal feed must be specified. The liquid metal flow rate was set to 3 times the molten salt flow rate to account for the rare earth and actinide fluorides being trivalent whereas lithium fluoride is monovalent. Temperature specifications in previous experimental studies range from 600 to $800^{\circ} \mathrm{C}$, and an initial value of $700^{\circ} \mathrm{C}$ was chosen for this model $[18,8]$. The results from the model can be seen below in Figure 2.

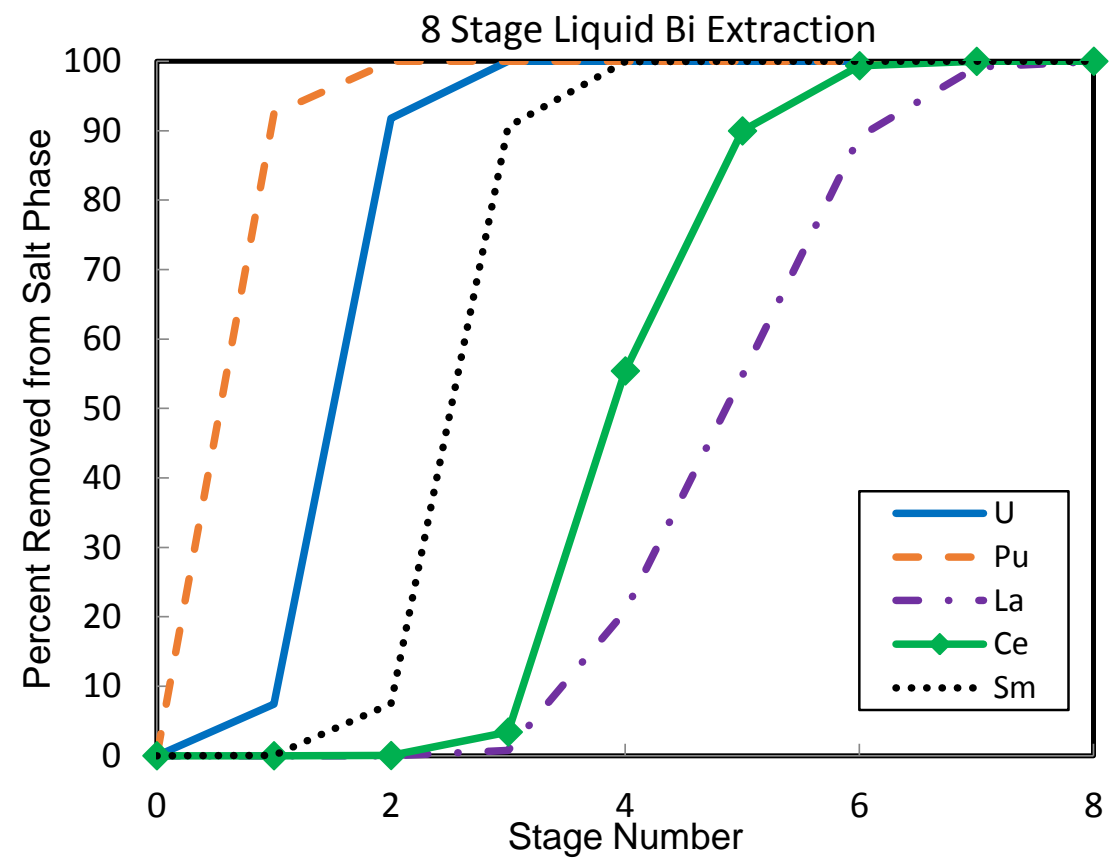

Figure 2. Percent removal of actinides and rare earths across extraction cascade at $700^{\circ} \mathrm{C}$ 
The figure above shows that as stage number is increased, the percent removal of all contaminants also increases. Therefore, with sufficient stages ( 8 with the current parameters), it is possible to remove greater than $99 \%$ of all contaminants. Additionally, it can be noted that the actinide elements, uranium and plutonium, are the first to be extracted, followed by the rare earths lanthanum, cerium, and samarium. This result is promising as the majority of the fuel materials can be recycled separately from the fission products. The fuel materials contained in the liquid bismuth could be removed and reused through another electrochemical transfer step with molten $\mathrm{LiCl}$ [2].

\subsection{Effect of Actinide and Rare Earth Concentrations in Salt}

Eq. 7 clearly shows that the actinide and rare earth concentrations have significant effect on the results. Two additional sets of compositions of the salt, i.e. $x(\mathrm{U})=x(\mathrm{Pu})=.001$, $x(\mathrm{La})=x(\mathrm{Ce})=x(\mathrm{Sm})=.0001 \quad$ and $\quad x(\mathrm{U})=5 x(\mathrm{Pu})=.005, \quad x(\mathrm{La})=x(\mathrm{Ce})=x(\mathrm{Sm})=.0001 \quad$ were calculated to basically represent two situations that actinide concentrations are larger than rare earths and $\mathrm{U}$ concentration is larger than $\mathrm{Pu}$. The extraction performances are shown as Figure 3 and Figure 4, respectively. The results show that lower rare earth concentration decreases the stage number needed for extracting them out and higher actinide concentration needs more stages to achieve a 99\% cleanup and will delay the extraction of rare earth elements. The exact results show significant difference for different compositions, while properties, such as removal percentage increases with stages, 99\% cleanup could be achieved with enough stages, and actinides are easier to be cleaned than rare earths are the same. Without a doubt that accurate and specific concentration input for every species will provide more trustworthy calculation results, however, due to the overall technology immaturity, such as lack of detailed fuel performance modelling and operation experience, there is no data existing in literature to provide the composition information [2]. The calculation results presently are only applicable to the assumptions in the paper. But they do give qualitative assessment to the issue of molten salt cleanup in FHR. Additionally, the model is pretty extendable. Once having data about composition leaked out from the fuel to salt, the model could be easily applied to get more practical results corresponding to the operation of FHR. Therefore, for the rest of this paper, the actinide and rare earth concentrations used are still .001 in mole fraction for the sake of simplicity. 


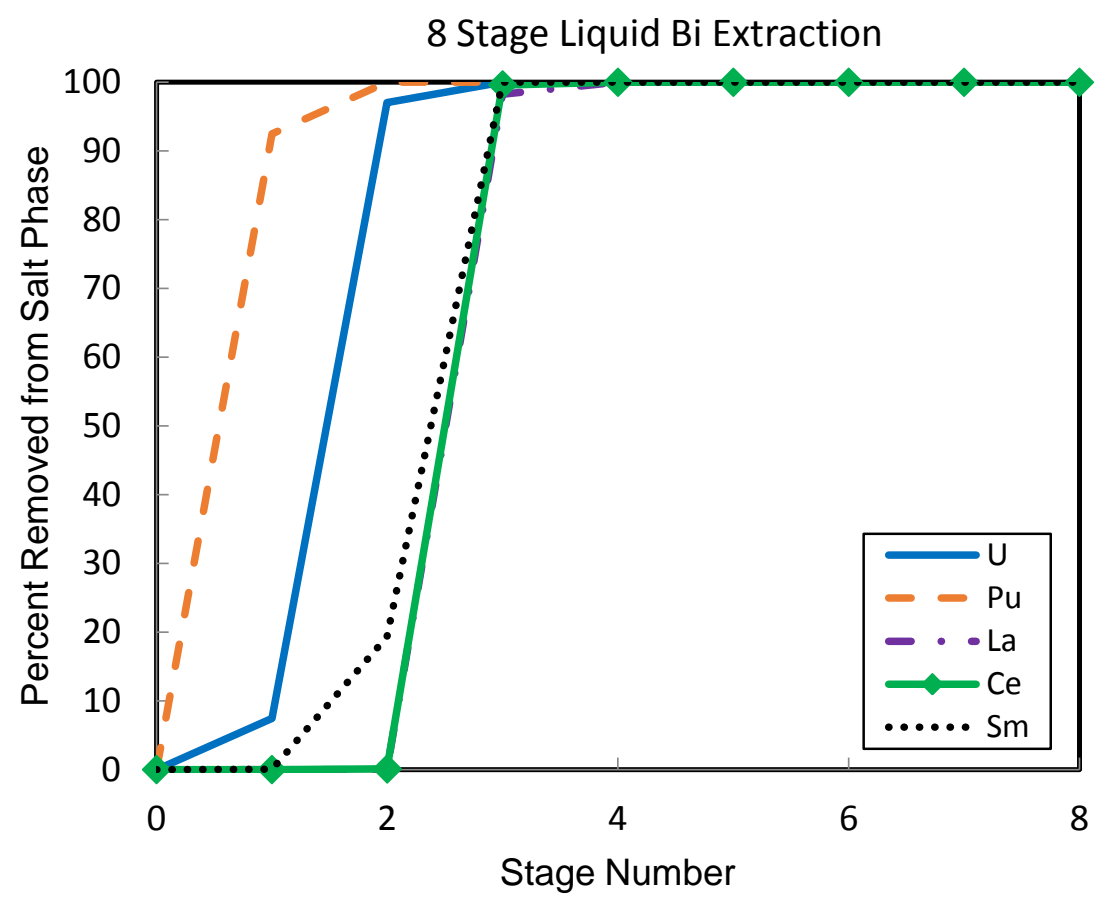

Figure 3. Percent removal of actinides and rare earths across extraction cascade with the composition of $x(\mathrm{U})=x(\mathrm{Pu})=.001$ and $x(\mathrm{La})=x(\mathrm{Ce})=x(\mathrm{Sm})=.0001$

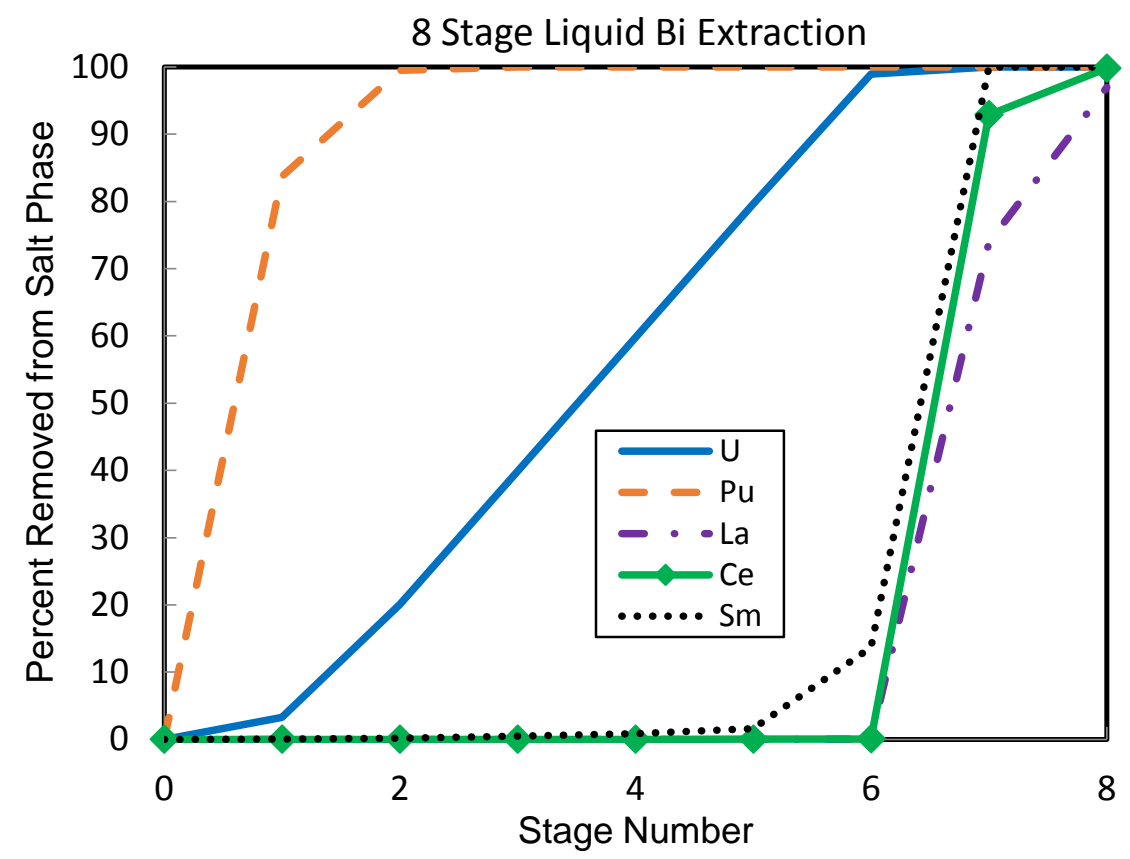

Figure 4. Percent removal of actinides and rare earths across extraction cascade with the composition of $x(\mathrm{U})=5 x(\mathrm{Pu})=.005$ and $x(\mathrm{La})=x(\mathrm{Ce})=x(\mathrm{Sm})=.0001$

\subsection{Effect of Lithium Concentration in Bi phase}


The effect of concentration of lithium initially in the metal phase was studied by varying the mole fraction in the model. The initial concentration was assumed to be a constant value across all stages. The model was run for two additional lithium mole fractions .0025 and .005 . Temperature remained at $700^{\circ} \mathrm{C}$. The results can be seen below in Figure 5 and Figure 6.

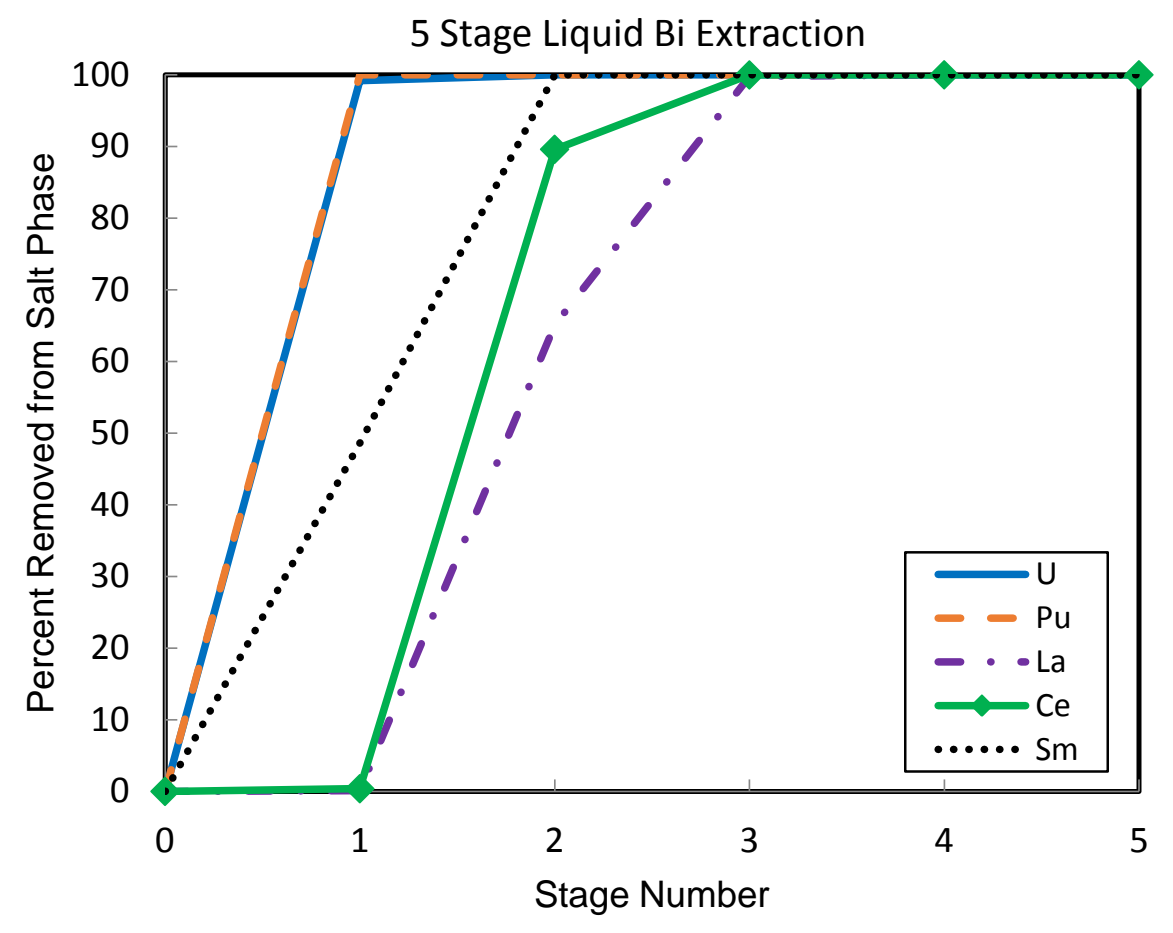

Figure 5. Percent removal across cascade at $700^{\circ} \mathrm{C}$ and .0025 initial mole fraction of $\mathrm{Li}$ in $\mathrm{Bi}$ phase 


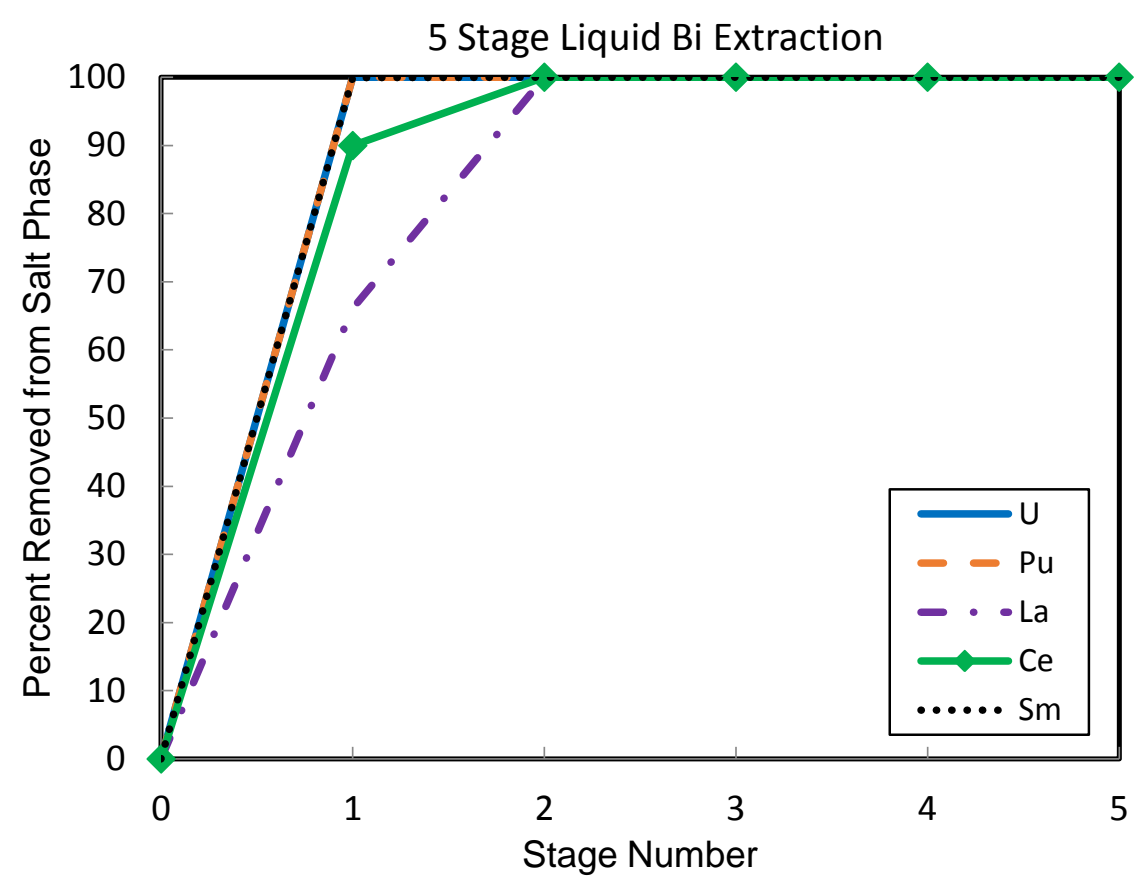

Figure 6. Percent removal across cascade at $700^{\circ} \mathrm{C}$ and .005 initial mole fraction of $\mathrm{Li}$ in $\mathrm{Bi}$ phase

As shown in the figures above, increasing the initial concentration of lithium in the Bi phase results in a higher effective extraction at each stage and therefore, fewer stages are required to reach a $99 \%$ removal of all contaminants from the salt. However, decreasing the number of stages also results in the simultaneous extraction of both rare earths and actinides. This consequence is undesirable as it would be favorable to recycle the fuel materials ( $\mathrm{U}$ and $\mathrm{Pu}$ ) separately. This can be solved by varying the initial lithium concentration in the Bi phase at each stage in the cascade. The concentration should be kept lower at the first few stages in order to separate out the $\mathrm{U}$ and $\mathrm{Pu}$ with as little rare earths as possible. The concentration of lithium can then be increased in the following stages to remove the remaining rare earth contaminants.

The model was used to show the distribution using a stage dependent initial Li concentration in the metal phase. The model was adjusted so that the initial Li mole fraction was .0005 in the first 4 stages, and all latter stages were raised to .0025 . The temperature was set to $700^{\circ} \mathrm{C}$ and all other parameters were left unchanged. Figure 7 below shows the results of this model. 


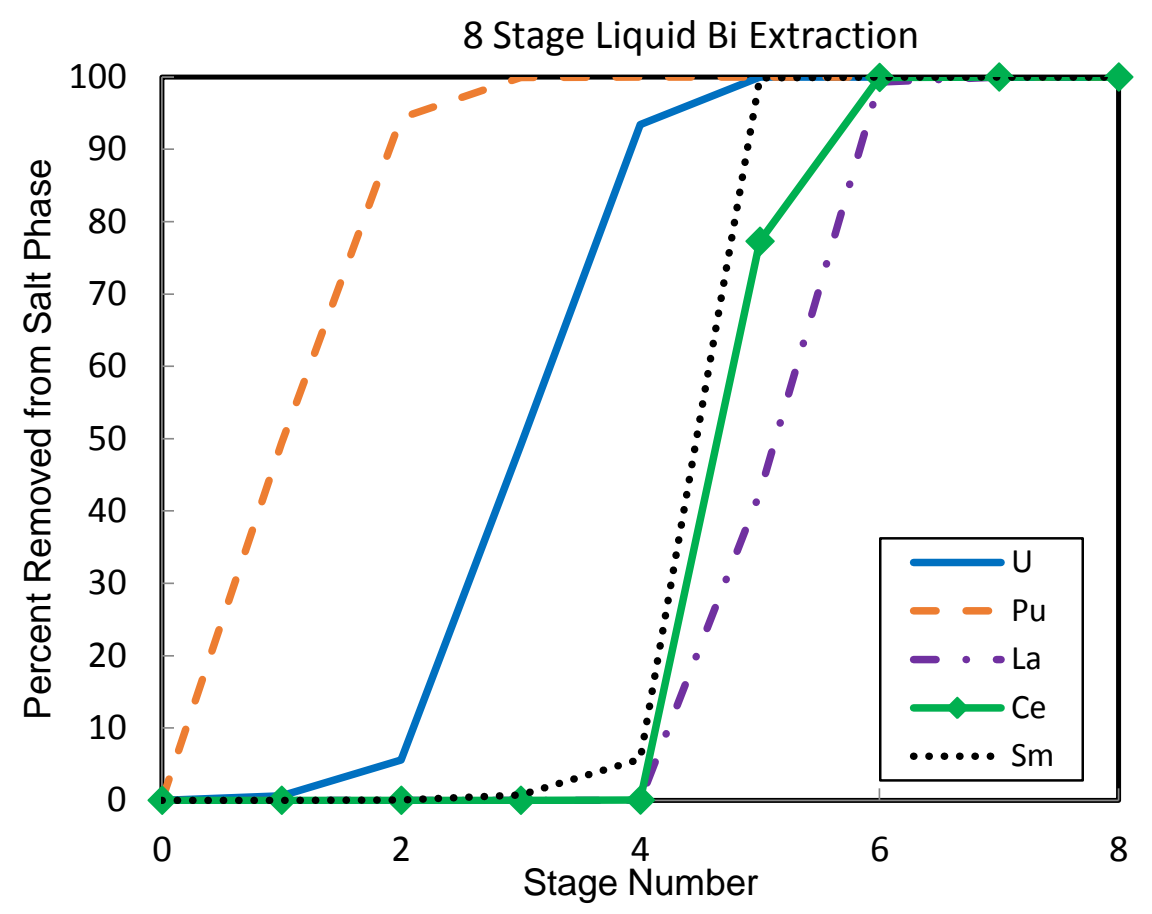

Figure 7. Percent removal across cascade at $700^{\circ} \mathrm{C}$ with stage dependent initial mole fraction of $\mathrm{Li}$ in $\mathrm{Bi}$ phase

As shown in the distribution plot above, this model produces a favorable result. Following stage 4, greater than $99 \%$ of $\mathrm{Pu}$ and $93 \%$ of $\mathrm{U}$ has been removed, while only $1 \%$ of all other contaminants have been extracted. Following stage 4, the initial Li concentration in the metal phase is increased, which allows for a more effective transfer of all other rare earths with fewer stages. This revised model predicts that 6 stages are sufficient to remove all contaminants, while still being capable of extracting the actinides separately from the rare earths.

\subsection{Effect of Flow Rate Ratio}

The ratio of the molten salt to liquid metal flow rates were also studied in this model by varying the liquid metal flow rate from 1 to 5 times the molten salt flow rate. The metal phase for each stage was specified to have a constant initial lithium concentration of .001 mole fraction. Additionally, the temperature was set at $700^{\circ} \mathrm{C}$. The model was run with all 5 elements set to an initial concentration of .001. The plots below in Figure 8 and Figure 9 show the distribution results for uranium and cerium for different flow ratios. The results for all other rare earths and actinides in the model show very similar trends 


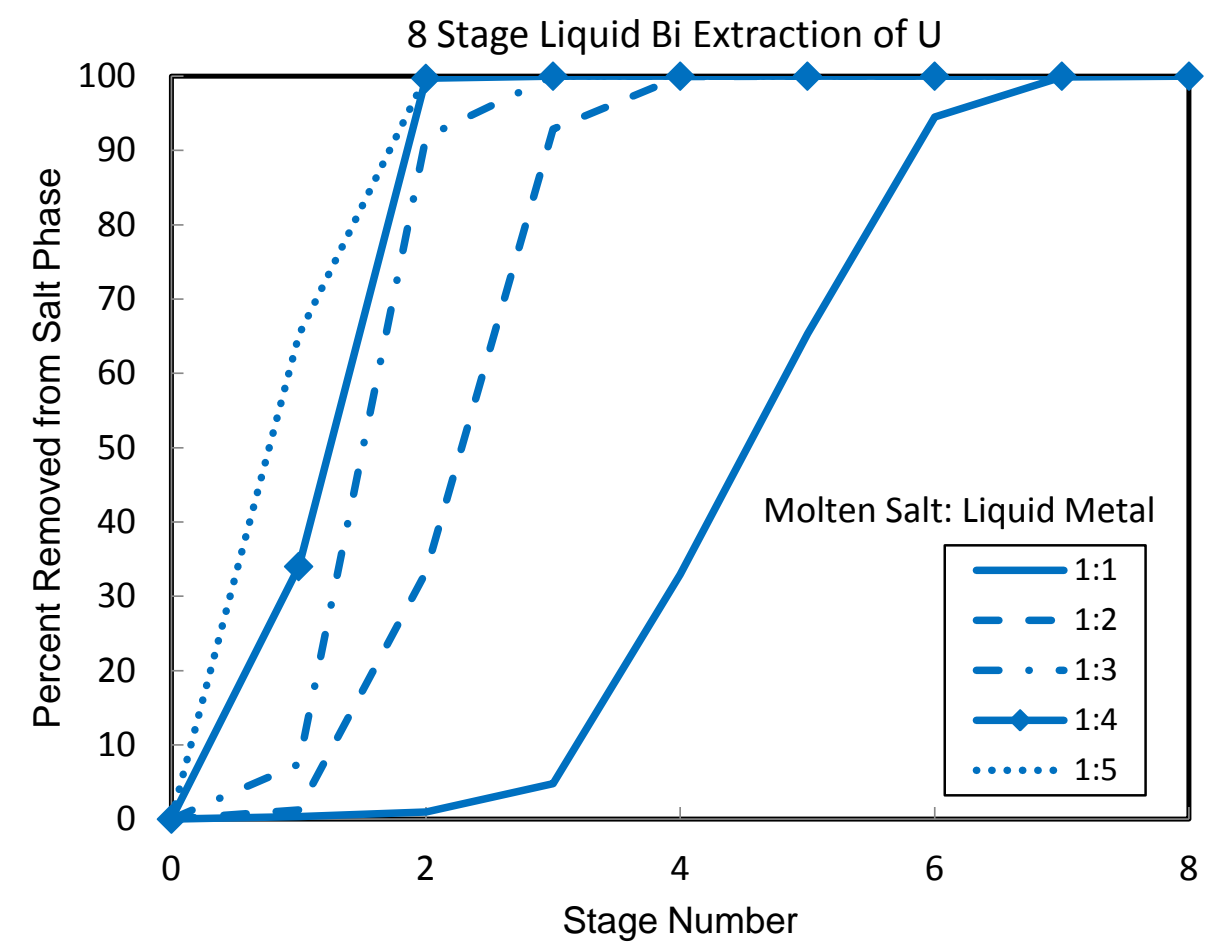

Figure 8. Percent removal of uranium across cascade at $700^{\circ} \mathrm{C}$ with varying flow rate ratios

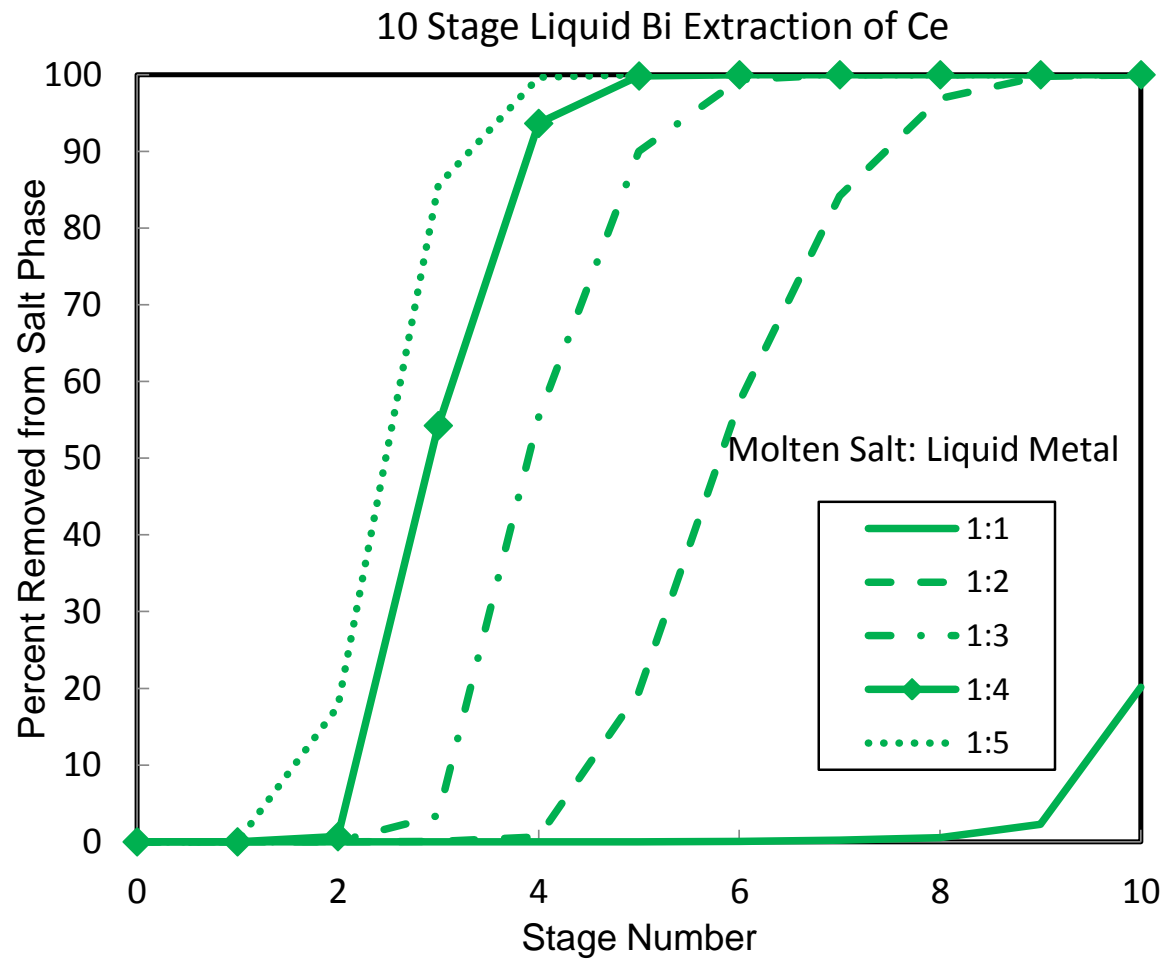

Figure 9. Percent removal of cerium across cascade at $700^{\circ} \mathrm{C}$ with varying flow rate ratios 
As can be seen by the plots for uranium and cerium, increasing the flow rate of the liquid metal phase increased the percent removal of contaminants across each stage. However, the relationship shows a decreasing exponential effect as the flow rate is increased. At low liquid metal flow rates, increasing the flow rate has a much greater impact on the distribution, but at higher flow rates, the same increase in flow rate has significantly less of an impact on the distribution across the cascade.

\subsection{Effect of Temperature}

Apparent potential and activity coefficient are both significantly affected by temperature based on the literature data provided in Section 2. Therefore, the effect of temperature on extraction across the cascade was also examined by varying the temperature in the model. The initial concentration on lithium in the $\mathrm{Bi}$ phase was assumed to be a constant value across all stages, and was set to .001 mole fraction. The model was run for varying temperatures ranging from 600 to $800^{\circ} \mathrm{C}$ and is plotted in Figure 10 shown below.

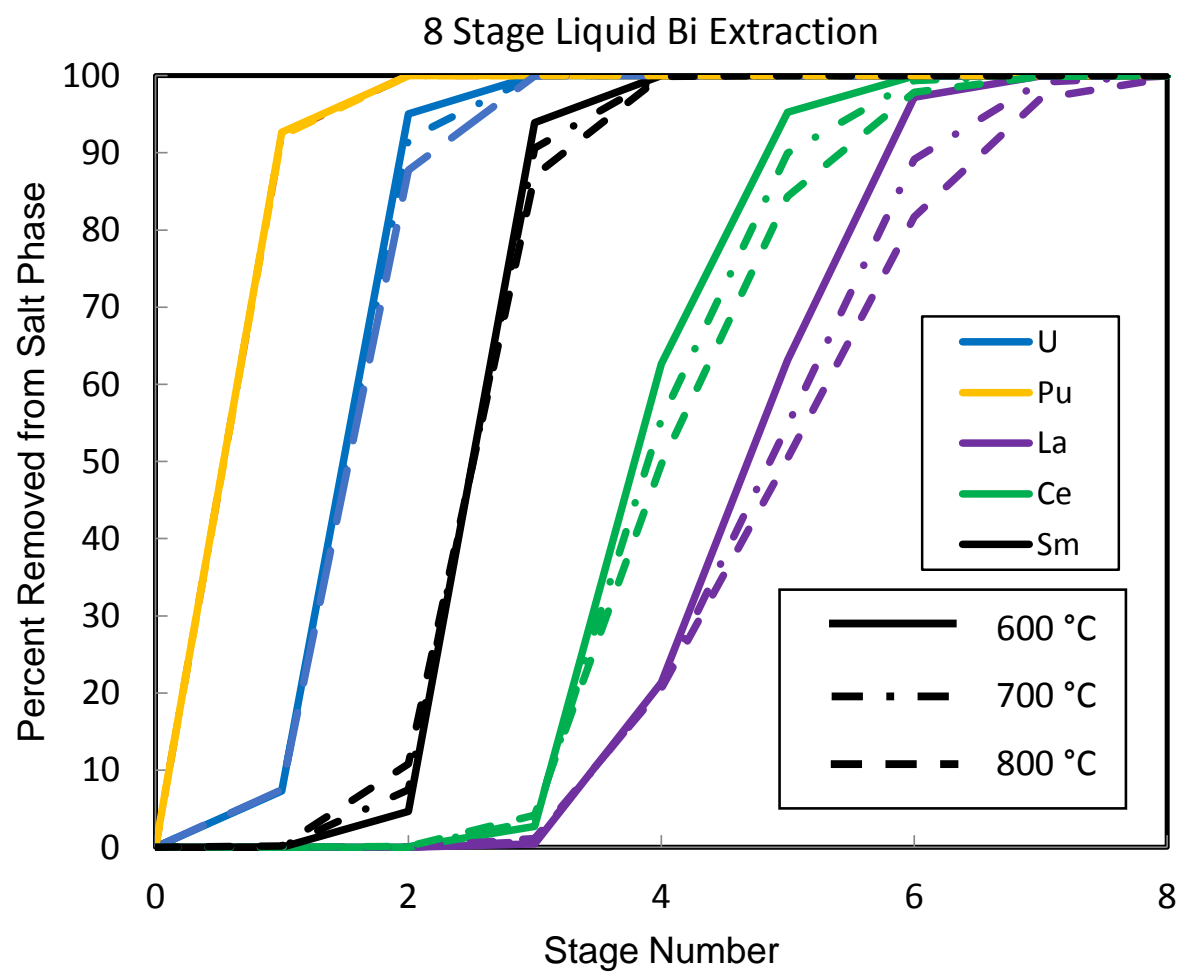

Figure 10. Effect of temperature on percent removal across extraction cascade

Based on the generated plot for varying temperature, it is evident that increasing the temperature results in a lower percent removal of the majority of contaminants at each stage. Plutonium seems to be the least affected by changing temperature, however the rare earth elements show a much more drastic effect. The results suggest that maintaining a lower 
system temperature will allow for the most effective extraction and require the least number of stages to achieve the desired removal of contaminants.

\section{Conclusion}

The likelihood of contamination into the primary coolant from leaked fuel major is a concern for FHR development. A possible solution to this contamination is to develop an online processing system for the primary coolant using a two phase extraction process with lithium activated bismuth as the extractant. A multistage extraction model has been developed for determining the distribution of possible actinides and rare earth elements between two phases of lithium activated bismuth and molten $\mathrm{LiF}-\mathrm{BeF}_{2}(66$ mole \% LiF). The model provides good evidence that this multistage system could be an effective method for removing contaminates from the coolant. Based on the results from the model, the major contributing factor in the distribution is the concentration of lithium in the bismuth phase. A higher concentration allows for a greater removal at each stage, however better separation between each actinide and rare earth can be achieved with a lower initial concentration of Li. The results suggest that by varying this initial concentration at each stage, fuel elements ( $U$ and $\mathrm{Pu}$ ) can be removed and recycled separately from the rare earth contaminants. The flow rate ratio between the molten salt and liquid metal phases was also studied, and showed that at lower liquid metal flow rates, increasing the rate has a large positive effect on the extraction of all contaminants; however, at larger flow rates, the effect is much less significant. Temperature effects were also studied and the model shows that lower temperatures result in a better extraction. However, the desired extraction can still be achieved at all temperatures within the designated range of 600 to $800^{\circ} \mathrm{C}$.

This model provides good insight to the development of a multistage extraction system for primary coolant clean-up in FHRs. However, additional improvements should be made to further this concept. First, liquid-liquid extraction kinetics must be considered, as the extraction rates are normally very slow and equipment to reduce equilibration time will need to be developed. Experimental data for other transuranic elements and fission products in $\mathrm{LiF}_{-\mathrm{BeF}_{2}}$ salt and in liquid $\mathrm{Bi}$ would allow this model to be extended to more than 5 elements. Currently, this data is not readily available in literature and further work is highly merited. Additionally, flow rate considerations and other time dependent processes in FHR operation are important parameters that still need to be studied more thoroughly. This model can be further expanded to include electrochemical kinetics in order to consider these parameters. 


\section{Acknowledgement:}

This research has been performed using funding received from the DOE Office of Nuclear Energy's Nuclear Energy University Programs (IRP 14-7476) 


\section{References}

[1] David E. Holcomb, George F. Flanagan, Gary T. Mays, W. David Pointer, Kevin R. Robb, and Graydon L. Yoder, Jr., Fluoride Salt-Cooled High-Temperature Reactor Technology Development and Demonstration Roadmap", ORNL/TM-2013/401, Oak Ridge, TN, September 2013

[2] Yoder, G. L., et al. "Advanced High Temperature Reactor Thermal Hydraulics Analysis and Salt Clean-up System Description." (2014).

[3] Holcomb, David E., et al. "Fluoride salt-cooled high-temperature reactor technology

development and demonstration roadmap." ORNL/TM-2013/401, ORNL, Oak Ridge,

TN (2013).

[4] Grimes, W. R., "Molten-Salt Reactor Chemistry," Nuclear Applications and Technology, 8, 137-155 (1970).

[5] Delpech, S. et al, "Reactor physic and reprocessing scheme for innovative molten salt reactor system," Journal of Fluorine Chemistry, 130, 11-17 (2009).

[6] Evan Wu, "Distribution model for molten salt clean up and actinide separation", ICAPP 2016. Apr.17-20, San Francisco, CA.

[7] A. V. Zagnit'ko, V.V. Ignat'ev, "Equilibrium Distribution of Lanthanum, Neodymium, and Thorium between Fluoride Salt Melts and Liquid Bismuth", Russian Journal of Physical Chemistry A, 208 2, Vol. 86, No. 4, pp. 533-538

[8] H. Moriyama, K. Yajima, N. Nunogane, T. Ohmura, K. Moritani, J. Oishi, "Reductive Extraction of Lanthanide and Actinide Elements from Molten LiF-BeF2 Salt into Liquid Bismuth", Journal of Nuclear Science and Technology, 21 (1984) p.949-958.

[9] J. D. Law, T. A. Todd, "Liquid-Liquid Extraction Equipment", Introduction to Nuclear Chemistry and Fuel Cycle Separations Course, Idaho National Lab, 2008

[10] C.F. Baes, The chemistry and thermodynamics of molten-salt-reactor fluoride solutions, Thermodynamics Vol.1, 1965, pp. 427.

[11] L. Martinot, Physics and Chemistry of the actinides, Molten-salt chemistry of actinides, chap. 4, 1991.

[12] W. R. GRIMES, et al, Chem. Eng. Prog., 55, No. 27 (1959) 65-70.

[13] W. T. WARD, et al, USAEC Report ORNL-2749, 1959.

[14] M. Kurata, Y. Sakamura, T. Matsui, Thermodynamic quantities of actinides and rare earth elements in liquid bismuth and cadmium, Journal of Alloys and compounds, 234, 8392, 1996.

[15] V. A. Lebedev, L. G. Babikov, S. K. Vavilov, I. F. Nichkov, S. P. Raspopin, O. V. Skiba, The thermodynamics of the system plutonium-bismuth, Atomnaya Energiya, 27 (1) 59-61, 1969. .

[16] J. Zhang, et al., Thermodynamic properties of actinides and fission products in liquid bismuth, Progress in Nuclear Energy, 81 (2015) 67-77

[17] M. S. Foster, et al., Thermodynamics of binary alloys. I. The lithium-bismuth system, Inorganic chemistry, 3 (1964) 1428-1431

[18] L. M. Ferris, J. C. Mailen, J. J. Lawrence, F. J. Smith, and E. D. Nogueira, Equilibrium Distribution Of Actinide And Lanthanide Elements Between Molten Fluoride Salts And 
Liquid Bismuth Solutions, Journal of Inorganic and Nuclear Chemistry, 32, 1970, pp. 20192035 